\title{
THE PARIS AGREEMENT AS A STEP BACKWARD TO GAIN MOMENTUM: LESSONS FROM AND FOR THEORY
}

\author{
Alejandro Caparrós
}

Dalloz | « Revue d'économie politique »

2016/3 Vol. 126 | pages 347 à 356

ISSN 0373-2630

Article disponible en ligne à l'adresse :

https://www.cairn.info/revue-d-economie-politique-2016-3-page-347.htm

Distribution électronique Cairn.info pour Dalloz.

(C) Dalloz. Tous droits réservés pour tous pays.

La reproduction ou représentation de cet article, notamment par photocopie, n'est autorisée que dans les limites des conditions générales d'utilisation du site ou, le cas échéant, des conditions générales de la licence souscrite par votre établissement. Toute autre reproduction ou représentation, en tout ou partie, sous quelque forme et de quelque manière que ce soit, est interdite sauf accord préalable et écrit de l'éditeur, en dehors des cas prévus par la législation en vigueur en France. Il est précisé que son stockage dans une base de données est également interdit. 


\title{
The Paris Agreement as a step backward to gain momentum: Lessons from and for theory
}

Alejandro Caparrós ${ }^{1}$

\begin{abstract}
The Paris Agreement has moved us backward from a world where binding burdensharing agreements like the Kyoto Protocol were the standard, to a world where climate policy is reduced to pledge and review. Nevertheless, this has allowed climate policy to gain new momentum. This paper argues that game theoretical analyses of International Environmental Agreements have not incorporated this change yet, as they were all designed to analyze burden sharing agreements, or agreements where signatories essentially become one player. Despite this fact, some relevant insights from this literature are still relevant to guiding future climate policy in the new context.
\end{abstract}

climate change - international negotiations - bargaining theory - game theory - international environmental agreements

\section{L'Accord de Paris comme un pas en arrière pour un nouvel élan : Les leçons à tirer de et pour la théorie}

L'Accord de Paris nous a déplacé d'un monde où les accords fermes de partage du fardeau, comme pour le Protocole de Kyoto, étaient standards à un monde où la politique climatique se réduit à l'engagement et le réajustement. Cela a néanmoins permis de donner un nouvel élan à la politique climatique. Dans ce papier nous soutenons que les approches en termes de jeux n'ont pas encore intégré ce changement dans la mesure où elles ont été conçues pour analyser les accords sur le partage du fardeau, ou encore les accords où les signataires finissent par ne faire qu'un. Malgré cela, certains éléments marquants de cette littérature conserve toute leur pertinence pour guider la politique climatique future dans ce nouveau contexte.

changement climatique - négociations internationales - théorie de la négociation théorie des jeux - accords environnementaux internationaux

Classification JEL : C78, H41, 054

1. Director, Institute for Public Goods and Policies (IPP), Consejo Superior de Investigaciones Científicas (CSIC), Madrid (Spain). E-mail: alejandro.caparros@csic.es

I gratefully acknowledge the financial support from the MEC (Spanish Ministry of Economy and Competitiveness), through the project ACBPA (ECO2012-35432). The ideas presented in this paper have greatly benefitted from discussions with several colleagues, in particular Tarik Tazdaït, Jean-Christophe Péreau and Michael Finus. The comments of an anonymous referee are also gratefully acknowledged. 


\section{Introduction}

Despite the celebrations when negotiations ended successfully at COP 21 in December 2015, the Paris Agreement (henceforth, "the Agreement") adds relatively little to the United Nations Framework Convention on Climate Change ("UNFCCC" or "the Convention"), which was signed and ratified by almost every country in the world over twenty years ago. And yet, it remains an important agreement for the motives that we will discuss below.

In 1992 almost every country in the world, including the US and China, agreed that the ultimate objective of the Convention was the "stabilization of greenhouse gas concentrations in the atmosphere at a level that would prevent dangerous anthropogenic interference with the climate system", adding that this level should be achieved within a time-frame sufficient to allow ecosystems to adapt naturally to climate change and to enable economic development to proceed in a sustainable manner (UNFCCC [1992]). The Agreement has added that to achieve this goal, countries aim at "holding the increase in the global average temperature to well below $2{ }^{\circ} \mathrm{C}$ above pre-industrial levels and [...] pursue efforts to limit the temperature increase to $1.5^{\circ} \mathrm{C}$ above pre-industrial levels" (UNFCCC [2015]).

The Agreement does not have short-term commitments, but rather it urges countries to periodically send their voluntary commitments, their Intended Nationally Determined Contributions (INDCs). Concerning this issue, the Convention stated that developed countries "shall communicate [...] periodically [...] detailed information on its policies and measures [...], as well as on its resulting projected anthropogenic emissions by sources and removals by sinks". Developed counties also recognized in the Convention "that the return by the end of the present decade to earlier levels of anthropogenic emissions [...] would contribute to modifying longer-term trends in anthropogenic emissions consistent with the objective of the Convention." The important novelty of the Agreement is that developing countries must now also send their INDCs, but without specific individual obligations beyond the collective aim, in order "to reach global peaking of greenhouse gas emissions as soon as possible, recognizing that peaking will take longer for developing country Parties, [...] so as to achieve a balance between anthropogenic emissions by sources and removals by sinks of greenhouse gases in the second half of this century". Nevertheless, the Agreement clearly states that INDCs are not legally binding.

In other words, the Convention and the Agreement share an ambitious goal, which, if carried out, would mitigate the climate change problem. However, none of these instruments contains legally binding quantitative goals. In addition, no one is to blame if the target is not met. As there are no specific commitments for countries, there is no particular country to blame if the global target is not met.

All this accounted for, why is the Agreement important? In the early nineties there was an intense debate about the best way forward in order to stem global emissions. The first alternative considered was "pledge and review", 
meaning that countries would send their pledges and the international community would then review whether or not the goals were attained. The second alternative was to negotiate individual quantitative commitments. The latter was selected and used in the Kyoto Protocol in 1997 (a development of the Convention). This path was much more ambitious, but it came at a very high price. Individual quantitative commitments were set only for developed countries, leaving out those countries which would soon become the major emitters (China and India). What's more, the United States, the largest emitter at the time, did not ratify the agreement. In the following years, Canada and other countries left the Kyoto Protocol, and by the time the Paris Agreement was negotiated in 2015, only a handful of countries remained on the path initiated by the Kyoto Protocol (essentially the European Union and New Zealand). Thus, importance of the Agreement comes from the fact that it has taken us back to the starting line, giving us a second chance. On the road to the Paris Agreement, countries decided to return to the "pledge and review" alternative, where each country sends its proposed abatement effort (its INDC) and the international community limits itself to certify the achievement, or failure, of those INDCs. The novelty is that all countries in the world are now committed to send their INDCs, although developed countries are still recognized as having a special responsibility (motivated by their historical responsibility in terms of emissions). This approach is less ambitious than a binding burden-sharing agreement, but the advantage is that the Agreement covers $96 \%$ of current emissions, while the successor to the Kyoto Protocol only covered $14 \%$.

Before briefly reviewing some lessons that we may learn from theoretical analyses, I will describe other relevant features of the Agreement. Although not one of the most celebrated, Article 6 may become one of the most important articles in the long term. It states that countries may cooperate voluntarily to increase the reach of their abatement targets. Cooperation between countries can significantly reduce costs and allow for more ambitious goals, and Article 6 allows for bilateral and regional agreements. Experience has taught us that cooperation is almost impossible at the global level, but it may well be possible among a small group of countries. This article, together with the provision that INDCs will be reviewed every five years (see Article 4), provides hope that future levels of greenhouse gas abatement will be sufficient to keep the increase in average temperature below $2^{\circ} \mathrm{C}$ (the current INDCs imply an increase of about $3^{\circ} \mathrm{C}$ ). Article 9 is also relevant as it considers monetary transfers from developed countries to assist developing countries in their efforts to mitigate and adapt to climate change. Developed countries have agreed to mobilize a substantial amount of money, although this commitment does not appear within the Agreement, but as a part of the Decision, which reduced its legal force as only the Agreement will go through the ratification process. In addition, this commitment is carefully worded to minimize any binding interpretation and, as for targets, this global financial goal is not broken down into individual contributions. The approved text is as follows: "prior to 2025 the Conference of the Parties [...] shall set a new collective quantified goal from a floor of USD 100 billion a year".

Taking all this into account and bringing it into a game theoretic perspective, what game is the world going to play from now on? There will be no 
burden sharing agreement in the decades to come, and only bilateral or regional agreements may be binding. However, countries will need to build trust with each other in order to increase the reach of their targets if we ever want to meet the $2^{\circ} \mathrm{C}$ goal (let alone the $1.5^{\circ} \mathrm{C}$ goal). If countries set ambitious targets and systematically fail to meet them, trust between countries will fade. Setting targets that correspond essentially to business as usual (the Nash equilibrium) will not do the trick either, as we will fail to meet the global target and the ultimate objective of the Convention. Then, how can we foster cooperation in a world without burden sharing agreements? Let us see if theory can be of some help.

\section{Lessons from and for theory}

A large body of literature on game-theoretic analyses of International Environmental Agreements (IEA) has emerged over the last two decades. A recent survey and a selection of the most relevant papers can be found in Finus and Caparrós [2015]. A survey focused on those papers dealing with the negotiation process can be found in Caparrós [2016]. Here, I briefly discuss a handful of features and results from this literature that are relevant as we consider whether or not it can help us predict possible future developments of the Paris Agreement.

The literature on IEA can be divided into four broad categories (Finus and Caparrós [2015]). First, we have literature based on the concept of the internal and external stability of a coalition (agreement), in the sense that no player wants to leave or join the coalition (Carraro and Siniscalco [1993]; Barrett [1994]). Results show that for identical players, only a very small number of players form a coalition, while asymmetries among players allow for larger coalitions. The second approach is based on cooperative game theory and, more precisely, on the core (Chander and Tulkens [1997]). The objective is to set up a burden-sharing rule that is able to favor the cooperation of all, ensuring that the rule prevents any individual country, but also any sub-group of countries, from being interested in leaving the IEA. The two approaches just mentioned are static but there is also a large set of papers that have focused on the dynamic nature of the climate change problem (van der Ploeg and de Zeeuw [1992]). The papers in this third approach are characterized by using dynamic state-space games to analyze IEA, combined with one of the stability concepts discussed above. The fourth approach focuses on the negotiation process (Caparrós et al. [2004]), a part from which the previous approaches abstract. Here the goal is to investigate the impact of different bargaining protocols on the final agreement.

The principal common characteristic of this literature is that the papers, almost without exception, implicitly assume a burden sharing agreement, as the Kyoto Protocol was. In the long list of papers pioneered by Carraro and Siniscalco [1993] and Barrett [1994], countries determine their emissions jointly once they sign the agreement (all signatories essentially become one

REP 126 (3) mai-juin 2016 
player). It was a heroic assumption to model a treaty like the Kyoto Protocol, as it implies a degree of collaboration between signatories that is unheard of at the international level (except maybe for the treaties forming the European Union). But, for the Paris Agreement, where all countries simply send their intentions and there is no burden sharing agreement, the assumption is completely inadequate. The papers following Chander and Tulkens [1997] assume that a supranational authority imposes abatement efforts and transfers, ensuring that all players, and all groups of players, are better off with the proposed burden sharing rule. The agreement is then enforced by a threat to go back to all-singleton behavior. Again, the bottom-up approach decided upon in Paris, where countries send their proposal and breaking the agreement has no consequence, is far away from these assumptions. Papers in the bargaining tradition (Caparrós et al. [2004]) assume that agreements are binding, or alternatively, that defection of one player will bring all back to the all-singleton behavior. This was already a strong assumption for the Kyoto Protocol, as even "binding" agreements under international law are not really binding in the same way that a contract is, because each country maintains the option to denounce the agreement and end its participation. However, this assumption is much harder to sustain for INDCs, as they are not even binding under international law, and there is no reason to believe that countries will abandon their intended abatement efforts because one country decides to do so.

The bottom line is that the world has moved away from burden sharing agreements and relatively binding agreements and has embraced instead the "pledge and review" alternative. Theoretical analyses have not yet incorporated this tendency. Future analyses need to be dynamic in nature, as the process initiated in Paris will take a considerably amount of time to come to fruition. However, more importantly, future models need to analyze how to best sustain cooperation in a world without burden sharing agreements. In this regard, the Paris Agreement is closer to "cheap talk" than to a binding agreement.

Cheap talk is used in game theory to refer to communication that is costless, non-binding and unverifiable (Crawford and Sobel [1982]; Farrell and Rabin [1996]). Most game theoretic analyses deal with situations where information is shared via "signaling", as discussed by Spence [1974], where an informed agent takes costly actions that reveal its information or "type" (applied to IEA, see Caparrós et al. [2004], Espinola-Arredondo and MuñozGarcía [2011] or Jakob and Lessmann [2012]). In the context of bargaining, such an action either directly imposes costs of delay and/or directly affects payoffs by constituting an offer that is binding if the other player accepts it. With cheap talk, in equilibrium different types have incentives to choose different cheap-talk messages, but no part of these incentives consists of exogenous costs or benefits (Farrell, and Gibbons [1989]). Congleton [2001] already discussed, in the context of IEAs, whether or not environmental treaties should be considered cheap talk. His conclusion was that at least for some IEAs, such as the Convention, the content seems consistent with a cheap talk interpretation. However, he also argued that a cheap talk interpretation implies that all countries should sign the treaty. According to Congleton, "no treaty has achieved the "unanimous" support that a cheap talk interpretation seems to imply". The problem with this argument is that 
the Convention and the Agreement have indeed achieved what is essentially "unanimous" support. Hence, not only the content, but also the universal adoption, favor a cheap talk interpretation.

In any case, even cheap talk can have an impact in many games. For bargaining games, Farrell and Gibbons [1989] show that cheap talk, in their case in an initial phase before more serious (binding) negotiations take place, can have an impact on the final outcome. Furthermore, they show that some outcomes can only be sustained as equilibria if there is cheap talk. In the same line, Farrell [1987, 1988] experimentally studies simple sequential games where an underlying game is preceded by one or more rounds of structured pre-play cheap talk, in which players make non-binding announcements about their intended decisions (see Crawford [1998] for a survey of the experimental literature on cheap talk). In Farrell [1988] one player makes non-binding suggestions about all players' decisions in the game. Suggestions that are consistent with rationality and the players' beliefs are believed, and all other suggestions are ignored (Farrell [1987] obtained qualitatively similar results). These models could be applied to IEA to analyze a situation like the Convention (cheap talk) followed by the Kyoto Protocol (binding negotiation). However, the situation is different for the Agreement, as there is no binding negotiation in sight. Whether cheap talk can have any influence on behavior in this case is unclear, as cheap talk has not always an impact on the final outcome (theoretical analyses show that in general it has an impact in coordination games where the interests are at least partially aligned, while it has no impact when there are opposing interests, as in the prisoner's dilemma). Although none of the models available is directly applicable to the situation created by the Agreement, the results in Farrell [1987, 1988] suggest that intentions need to be consistent with rationality and the beliefs of the players to have any impact on the outcome of the game. Absent a more detailed analysis, in particular a dynamic analysis with no binding phase afterwards, as the scenario opened by the Agreement, this suggest that INDCs (intentions) may have an impact on the final outcome if they are credible, while they will be simply ignored if they are over-ambitious.

Apart from the literature on cheap talk just mentioned, there is a large body of work that considers the role that conditional cooperation, punishment, communication, and endogenous group formation has on sustaining cooperation (see Chaudhuri [2011] for a survey focused on experimental results for the linear public good game). The IEA literature will need to incorporate and adapt these results to be relevant for the post-Paris world.

That said, and accepting this limitation, can we learn anything from existing literature on IEA and game theory that is still relevant? Bargaining games, whether based on the Nash bargaining solution or on the Rubinstein bargaining solution, are extremely optimistic, as countries reach an efficient agreement immediately. If Rubinstein's solution is used, the burden-sharing rule is determined by the discount factor (Caparrós et al. [2004]). However, as in any bargaining game, this discount factor is not related to financial interest rates and one should rather see it as an indicator of the countries' patience and how eager they are to reach an agreement. Hence, if one party has the possibility to signal that it is not particularly interested in reaching 
an agreement to tackle climate change before the game starts, or that it is in no hurry, it has every incentive to do so. In other words, countries have a strong incentive to declare that they prefer to wait until the science is completely settled before reaching any agreement (the US position in the first years of this century). This intuition is also at the basis of the developments in Beccherle and Tirole [2011] or Harstad [2012 and 2015]. These studies show that countries have an incentive to under-invest in clean technologies before negotiations start in order to gain bargaining power. As pointed out by Benedick [2007], "it is ironic that governments were negotiating emission-reduction targets while simultaneously reducing their budgets for energy technology R\& D". Although less severe than it was before Paris, this problem may still apply to future investment decisions and future submissions of more ambitious INDCs (Article 4).

As stated above, bargaining theory and signaling games are not as relevant for the analysis of a global agreement in a post-Paris world, as it is unlikely that a new global binding agreement will be attempted. Nevertheless, Article 6 allows for bilateral and regional agreements that can well be binding, or at least as binding as international agreements can be. Basic theory predicts that these agreements will be signed immediately, but as discussed in Caparrós et al. [2004], asymmetry of information explains why these agreements will need a considerable amount of time to be negotiated. Negotiations are delayed because countries use the offers and counter-offers process to gain information about the real characteristics of the other parties. In a simple model where only one variable is private information, and it can only take two possible values, the delay is modest. However, in practice, with many relevant variables and many possible levels this process can take much longer.

Caparrós and Péreau [2015] explore an alternative path that might still be relevant in a post-Paris world. The authors consider gradual coalition formation where a leader country, for example the EU, gradually extends a binding agreement, following a similar pattern to that observed for trade agreements. This alternative could co-exist with a global agreement based on pledges and is therefore a path worth exploring. These agreements could be signed as a development of Article 6, but could also be part of a development of the financial transfers to developing countries proposed in Article 9. These agreements would need to be negotiated between developed and developing countries. Furthermore, as Gatti et al. [2011] have correctly argued in the context of biodiversity negotiations, any agreement that fails to acknowledge the (increasing) bargaining power of the South will be perceived as unfair and is therefore doomed to fail. Offers need to take into account that both parties have bargaining power, essentially sharing the additional gains. Thus, if an offer fails to do so because it corresponds to a take-it-or-leave-it offer, where the proposer appropriates the entire additional surplus, it will be rejected (Gatti et al. show that the "incremental cost" contract set up under the Convention on Biodiversity falls into this category).

Moreover, as Shum [2014] shows, the bargaining power of some key players (China in his analysis) may in fact be increasing over time, so that they have no incentives to reach an agreement soon, unless the other party(ies) accept that this increasing bargaining power implies that it has to be already taken into account in any feasible deal today. As the author dis- 
cusses, this is unlikely in political terms. In Shum's [2014] analysis the gain in bargaining power from China comes from the fact that it is responsible for an ever-growing share of global emissions, so that each year it is becoming a more important player. In other words, with each year that passes it becomes more relevant to have China on board of any meaningful agreement. As expected, this fact has already had an impact on the road to the Paris Agreement, and one can only imagine that this will continue to be true in the future. In fact, from a bargaining theory perspective one should also expect that the countries that may partially gain from climate change, because their current climate is cold and extreme, are also interested in waiting before signing any significant climate deal. The reason is that the disagreement point of the remaining players is deteriorating rapidly while their own disagreement point is deteriorating less, or altogether improving. This could explain, for example, the reduced enthusiasm that Russia has consistently shown over the long history of the climate negotiations.

Analyses of unilateral actions also remain relevant for a post-Paris world, as some countries may decide unilaterally to be more ambitious than others (as the $\mathrm{EU}$ has done) or may consider in the future to unilaterally enhance the level of ambition of their INDCs (see Article 4 of the Agreement). Hoel [1991] has shown that unilateral actions are generally not effective, because they trigger lower abatement efforts in other countries. However, Brandt [2004] has argued that unilateral actions can be effective if they are used to signal that costs are relatively low. Along the same line, Benedick [2007] argued that the unilateral action taken in the late 1970s by a "loose coalition of like-minded nations", formed by Australia, Canada, Norway, Sweden, and the US, to individually and separately ban the use of CFCs in aerosol spray cans, demonstrated to skeptics that reducing emissions was feasible at a reasonable cost. In fact, it paved the way for the signing of the Montreal Protocol a decade later. Whether these results would also work for climate change is unclear. Costs related to climate policy have in fact been rather modest in Europe, especially for the sectors included in the EU emission trading system, although the reason for the low prices observed are far more complex than modest abatement costs. However, the analysis in Brandt [2004] also requires that costs be clearly correlated and it is unclear whether the US or developing countries see the costs in Europe as relevant to them.

Finally, existing analyses show that the conditional pledge used by the EU on the road to the Cancun Agreement in 2010 is probably a better strategy than unconditional unilateral action. Before the meeting in Cancun, the EU approved its strategy until 2020 by committing to a $30 \%$ reduction in its 1990 emissions if other industrialized countries joined the effort, or a $20 \%$ if they did not. The INDC submitted by the EU for the Paris Agreement partially abandoned this strategy, as the conditional commitment was not quantified. The intended contribution sent to Paris was a $40 \%$ reduction in emissions in 2030 compared to 1990, but leaving the door open for a higher goal should the outcome of the negotiation warrant a more ambitious target. The analysis by Helm and Wirl [2014] has shown that conditional pledges are a good strategy (see also Bréchet et al. [2010]). Nevertheless, Helm and Wirl's results have to be taken with care, because they are developed assuming that the North has all the bargaining power, and this seems like an unrealistic assumption upon which to model international climate policy. 


\section{Conclusion}

The Paris Agreement has moved us backward from a world with binding burden sharing agreements, like the Kyoto Protocol, to a world where climate policy is reduced to pledge and review. Nevertheless, this has allowed climate policy to gain new momentum. Although some key theoretical results remain valid, theoretical analyses of International Environmental Agreements have not yet incorporated this change. Future analyses need to fully integrate this new context to guide the process initiated in Paris which will, hopefully, allow us to meet the ultimate objective of the Convention.

\section{References}

BARRETT S. [1994], Self-Enforcing International Environmental Agreements. Oxford Economic Papers 46: 878-894.

BECCHERLE J. and TIROLE J. [2011], Regional Initiatives and the Cost of Delaying Binding Climate Change Agreements. Journal of Public Economics 95(11-12): 1339-1348.

BENEDICK R. E. [2007], Avoiding Gridlock on Climate Change. Issues in Science and Technology 23(2).

BRANDT U. S. [2004], Unilateral Actions, the Case of International Environmental Problems. Resource and Energy Economics 26(4): 373-391.

BRÉCHET T., EYCKMANS J., GÉRARD F., MARBAIX P., TULKENS H. and VAN YPERSELE J.-P. [2010], The Impact of the EUs Carbon Emissions Reduction Proposals on the Stability of Global Climate Agreements. Climate Policy 10(2): 148-166.

CAPARRÓS A. [2016], Bargaining and International Environmental Negotiations. Environmental and Resource Economics DOI 10.1007/s10640-016-9999-0.

CAPARRÓS A. and PÉREAU J. C. [2015], Multilateral versus Sequential Negotiations over Climate Change. IPP-CSIC working paper 2015-09. Institute for Public Goods and Policies, Madrid.

CAPARRÓS A., PÉREAU J.-C. and TAZDAÏT T. [2004], North-South Climate Change Negotiations: a Sequential Game with Asymmetric Information. Public Choice 121(3-4): 455-480.

CARRARO C. and SINISCALCO D. [1993], Strategies for the International Protection of the Environment. Journal of Public Economics 52(3): 309-328.

CHANDER P. and TULKENS H. [1997], The Core of an Economy with Multilateral Environmental Externalities. International Journal of Game Theory 26(3): 379401.

CHAUDHURI A. [2011], Sustaining Cooperation in Laboratory Public Goods Experiments: A Selective Survey of the Literature. Experimental Economics 14(1): 47-83.

CONGLETON R. D. [2001], Governing the Global Environmental Commons: The Political Economy of International Environmental Treaties and Institutions. In 
Schulze, G. G. and Ursprung, H. W. (eds), Globalization and the Environment. Oxford University Press, New York.

CRAWFORD V. [1998], A Survey of Experiments on Communication via Cheap Talk. Journal of Economic Theory 78(2), 286-298.

CRAWFORD V. and SOBEL J. [1982], Strategic Information Transmission. Econometrica 50(6): 1431-1452.

ESPINOLA-ARREDONDO A. and MUÑOZ-GARCÍA F. [2011], Free-riding in International Environmental Agreements: A Signaling Approach to Non-Enforceable Treaties. Journal of Theoretical Politics 23(1): 111-134.

FARRELL J. [1987], Cheap Talk, Coordination, and Entry. Rand Journal of Economics 18(1): 34-39.

FARRELL J. [1988], Communication, Coordination and Nash Equilibrium. Economic Letters 27(3): 209-214.

FARRELL J. and GIBBONS R. [1989], Cheap Talk Can Matter in Bargaining. Journal of Economic Theory 48(1): 221-237.

FARRELL J. and RABIN M. [1996], Cheap Talk. Journal of Economic Perspectives 10(3): 103-118.

FINUS M. and CAPARRÓS A. [2015], Game Theory and International Environmental Cooperation: Essential Readings. Edward Elgar, Cheltenham.

GATTI R., GOESCHL T., GROOM B. and SWANSON T. [2011], The Biodiversity Bargaining Problem. Environmental and Resource Economics 48(4): 609-628.

HARSTAD B. [2012], Climate Contracts: A Game of Emissions, Investments, Negotiations, and Renegotiations. Review of Economic Studies 79(4): 1527-1557.

HARSTAD B. [2015], The Dynamics of Climate Agreements. Journal of the European Economic Association DOI:10.1111/jeea.12138.

HELM C. and WIRL F. [2014], The Principal-Agent Model with Multilateral Externalities: An Application to Climate Agreements. Journal of Environmental Economics and Management 67(2): 141-154.

HOEL M. [1991], Global Environmental Problems: The Effects of Unilateral Actions Taken by one Country. Journal of Environmental Economics and Management 20(1): 55-70.

JAKOB M. and LESSMANN K. [2012], Signaling in International Environmental Agreements: The Case of Early and Delayed Action. International Environmental Agreements: Politics, Law and Economics 12(4): 309-325.

VAN DER PLOEG F. and DE ZEEUW A. [1992], International Aspects of Pollution Control. Environmental and Resource Economics 2(2): 117-139.

SHUM R. Y. [2014], China, the United States, Bargaining, and Climate Change. International Environmental Agreements: Politics, Law and Economics 14(1): 83-100.

SPENCE A. M. [1974], Market Signaling: Informational Transfer in Hiring and Related Screening Processes. Harvard University Press, Cambridge.

UNFCCC [1992], United Nations Framework Convention on Climate Change. Available at unfcc.int.

UNFCCC [2015], Adoption of the Paris Agreement (FCCC/CP/2015/L.9/Rev. 1). Available at unfcc.int. 